\title{
A novel FOXO1-mediated dedifferentiation blocking role for DKK3 in adrenocortical carcinogenesis
}

\author{
Joyce Y. Cheng ${ }^{1 \dagger}$, Taylor C. Brown ${ }^{1 \dagger}$, Timothy D. Murtha ${ }^{1}$, Adam Stenman ${ }^{3}$, C. Christofer Juhlin ${ }^{3}$, \\ Catharina Larsson ${ }^{3}$, James M. Healy ${ }^{1}$, Manju L. Prasad ${ }^{2}$, Wolfram T. Knoefel ${ }^{4}$, Andreas Krieg ${ }^{4}$, Ute I. Scholl ${ }^{5}$, \\ Reju Korah ${ }^{1}$ and Tobias Carling ${ }^{1,6^{*}}$ (D)
}

\begin{abstract}
Background: Dysregulated WNT signaling dominates adrenocortical malignancies. This study investigates whether silencing of the WNT negative regulator DKK3 (Dickkopf-related protein 3), an implicated adrenocortical differentiation marker and an established tumor suppressor in multiple cancers, allows dedifferentiation of the adrenal cortex.

Methods: We analyzed the expression and regulation of DKK3 in human adrenocortical carcinoma (ACC) by qRT-PCR, immunofluorescence, promoter methylation assay, and copy number analysis. We also conducted functional studies on ACC cell lines, NCI-H295R and SW-13, using siRNAs and enforced DKK3 expression to test DKK3's role in blocking dedifferentiation of adrenal cortex.

Results: While robust expression was observed in normal adrenal cortex, DKK3 was down-regulated in the majority (>75\%) of adrenocortical carcinomas (ACC) tested. Both genetic (gene copy loss) and epigenetic (promoter methylation) events were found to play significant roles in DKK3 down-regulation in ACCs. While NCl-H295R cells harboring $\beta$-catenin activating mutations failed to respond to DKK3 silencing, SW-13 cells showed increased motility and reduced clonal growth. Conversely, exogenously added DKK3 also increased motility of SW-13 cells without influencing their growth. Enforced over-expression of DKK3 in SW-13 cells resulted in slower cell growth by an extension of G1 phase, promoted survival of microcolonies, and resulted in significant impairment of migratory and invasive behaviors, largely attributable to modified cell adhesions and adhesion kinetics. DKK3-over-expressing cells also showed increased expression of Forkhead Box Protein O1 (FOXO1) transcription factor, RNAi silencing of which partially restored the migratory proficiency of cells without interfering with their viability.

Conclusions: DKK3 suppression observed in ACCs and the effects of manipulation of DKK3 expression in ACC cell lines suggest a FOXO1-mediated differentiation-promoting role for DKK3 in the adrenal cortex, silencing of which may allow adrenocortical dedifferentiation and malignancy.
\end{abstract}

Keywords: DKK3, FOXO1, Adrenocortical carcinogenesis

\footnotetext{
* Correspondence: tobias.carling@yale.edu

${ }^{\dagger}$ Equal contributors

${ }^{1}$ Department of Surgery \& Yale Endocrine Neoplasia Laboratory, Yale University School of Medicine, New Haven, CT, USA

${ }^{6}$ Department of Surgery, Yale University School of Medicine, 333 Cedar

Street, FMB130A, New Haven, CT 06520, USA

Full list of author information is available at the end of the article
} 


\section{Background}

Adrenocortical carcinoma (ACC) is a rare $(0.5-2$ cases per million/year) endocrine malignancy that carries a poor prognosis at diagnosis due to its propensity to metastasize before detection. Even with aggressive surgical and oncologic therapy, the 5-year survival rate is an abysmal 16-38\% [1-4]. A major reason for the lack of an effective targeted treatment strategy for ACCs is an inadequate understanding of the molecular pathogenesis of the disease $[3,4]$.

Genetic and epigenetic dysregulations of the WNT, p53, and IGF2 pathways appear to dominate various cancerdriving anomalies in the majority of ACCs [5-7]. Recent findings from comprehensive genetic analyses of ACCs confirmed a signature role for WNT dysregulation in the origin and/or progression of ACCs [4, 6, 8, 9]. Physiologically, both canonical and non-canonical WNT signaling pathways play global and zone-specific roles in the development, differentiation, and homeostasis of the adrenal gland $[10,11]$. In particular, endocrine homeostasis of the adrenal glomerulosa and fasciculata zones is largely controlled by WNT-differentiation signaling mediated by the Wnt4-Fz1/2-Dvl3- $\beta$-Catenin-SF1 axis [12-16]. Regulatory components of this proposed adrenal cortex-specific Wnt4 axis include the secretory factors, frizzled-related protein 1 (SFRP1) and the putative tumor suppressor, DKK3 [14, 17, 18]. Aberrant WNT signaling has been well-established in the origin of many tumor types and is strongly associated with stabilization of $\beta$-catenin in the cytoplasm and/or in the nucleus and constitutive activation of WNT target genes [19, 20]. Similar stabilization and nuclear accumulation of $\beta$-catenin is seen in benign adrenocortical adenomas (ACAs) and frequently in malignant ACCs $[10,21]$. However, only $10 \%$ of ACCs with constitutively active $\beta$-catenin carry mutations in the $\beta$-catenin gene (CTNNB1), suggesting alternate mechanisms of aberrant WNT activation, including dysregulation of WNT inhibitors such as Wif-1 [22]. Other WNT regulatory mutations found in ACCs include PRKAR1A [23] and recently identified KREMEN1 and ZNRF3 gene deletions [8, 24].

Although implicated in zonal differentiation and hormone biosynthesis $[14,25]$, a definitive role for the ubiquitous WNT inhibitor DKK3 in promoting functional differentiation and/or blocking tumor dedifferentiation of the adrenal cortex has yet to be clarified. The inhibitory role of DKK3 in WNT signaling is context-dependent and appears to be influenced by a repertoire of cell surface receptors and co-expressed ligands [26]. DKK3, a 38 kDa secreted glycoprotein with an $\mathrm{N}$-terminal signal peptide, is also implicated in eliciting distinct intracellular roles in addition to its secretory functions [27]. Reduced DKK3 expression is observed in a variety of solid tumors, and reexpression studies in multiple cancer cell types mostly resulted in cell cycle arrest and/or apoptosis, strongly suggesting a global tumor suppressor role for this WNT regulator (reviewed in [26]). Furthermore, ectopic expression of DKK3 in a variety of cancer cell types stifled aggressive malignant behavior, reversed epithelialmesenchymal transition (EMT), and impaired cell motility, pointing towards a comprehensive dedifferentiationblocking role for DKK3 [28, 29]. This study investigates a potential tumor suppressor role for the implicated adrenal differentiation factor DKK3 in blocking dedifferentiation of adrenocortical cells.

\section{Methods}

\section{Tissue acquisition}

Written informed consent was obtained from patients prior to surgical resection of adrenal tissue according to protocols approved by Institutional Review Boards at (a) Yale University, New Haven, CT, USA, (b) Heinrich Heine University Düsseldorf, Düsseldorf, Germany, and (c) Karolinska Institutet, Stockholm, Sweden. Tissue samples were flash-frozen (FF) in liquid nitrogen and stored at $-80{ }^{\circ} \mathrm{C}$ until processed for study. Specimens displaying unequivocal histopathological characteristics of ACCs $(n=38)$ and histologically normal adrenal tissue $(n=14)$ samples excised with ACAs were selected for study. Consecutive unstained/hematoxylin \& eosin (H\&E) stained $5 \mu \mathrm{M}$ sections of formalin-fixed, paraffin-embedded (FFPE) tissue samples underwent immunohistochemistry analyses. All samples were histopathologically confirmed by experienced endocrine pathologists before processing.

\section{DNA, RNA, and protein preparation}

Genomic DNA and total RNA were isolated from FF samples using AllPrep DNA/RNA/Protein Mini Kit (Qiagen) as per manufacturer's recommendations. Quantity and quality of prepared nucleic acids were assessed by spectrophotometry (NanoDrop Technologies, Inc.). Total protein from cultured cells was extracted using Laemmli buffer (BioRad) as cell lysis buffer; protein concentrations were quantified using Pierce BCA Protein Assay Kit (ThermoFisher Scientific) and GloMax multidetection system (Promega), as per manufacturer's instructions.

\section{Gene expression analysis}

Total RNA (100 ng) was reverse transcribed using iScript cDNA synthesis kit (Bio-Rad) as per manufacturer's instructions. Quantitative real-time PCR (qRT-PCR) was performed in triplicate using TaqMan PCR master mix with FAM fluorophore and probe/primer pairs specific to human DKK3 (Hs00951307_m1), FOXO1 (Hs01054576_m1), and RPLPO (Hs99999902_m1) (ThermoFisher Scientific) according to manufacturer's cycling conditions using CFX96 thermal cyclers (Bio-Rad). Gene expression levels were normalized to mean RPLPO expression levels. Relative gene expression values were calculated using recommended 
Livak method (Bio-Rad). Fold-change expression values were calculated by base-two logarithmic transformations of relative gene expression values.

For pathway-focused gene expression analysis, (a) $\mathrm{RT}^{2}$ Profile PCR Array Human WNT Signaling Pathway and (b) $\mathrm{RT}^{2}$ Profiler PCR Array Human Transcription Factors were used according to protocol outlined in $\mathrm{RT}^{2}$ Profiler PCR Array Handbook (Qiagen). Briefly, 100 ng of DNAfree RNA from each sample was used for 84 target genes listed in gene lists (available at www.qiagen.com) using 96-well $\mathrm{RT}^{2}$ profiler array format D. cDNA was prepared using $\mathrm{RT}^{2}$ first strand kit and amplified using $\mathrm{RT}^{2}$ SYBR Green Mastermix (both from Qiagen) using CFX96 thermal cycler. Differential expression of target genes was calculated using $\Delta \Delta C_{\mathrm{T}}$ method on data web portal at www.SABiosciences.com/pcrarraydataanalysis.php.

\section{Methylation-specific PCR}

Methylation status of CpG island A of DKK3 promoter (Chr11:12029737-12030841) was assessed by MethylScreen technology using EpiTect Methyl II PCR Assay (Qiagen) as previously described [30]. Briefly, $125 \mathrm{ng}$ of genomic DNA was mock-digested or digested with methylation-sensitive and methylation-dependent restriction enzymes individually or together, and methylation status of target DNA sequence was measured using qRT-PCR with probes specific to target DKK3 promoter sequence. $\mathrm{C}_{\mathrm{T}}$ values were converted into percentages of unmethylated, intermediatemethylated, and hypermethylated CpG values using a quantitation algorithm from EpiTect Methyl II PCR Assay Handbook (Qiagen). Tissue samples were designated as hypermethylated ( $>5 \%$ alleles with hypermethylation), intermediate-methylated $(>5 \%$ alleles with intermediate methylation), or unmethylated (no methylation detected).

\section{DNA copy number analysis (CNA) by qRT-PCR}

DNA from 27 ACC samples that passed specified test quality criteria were analyzed in quadruplicate with TaqMan Copy Number Assay using a primer / probe pair specific to target gene $D K K 3$ or housekeeping gene RPPH1. Normal adrenal tissue was used for diploid (2n) reference. Copy numbers were predicted using CopyCaller software v2.0 (ThermoFisher Scientific). TaqMan Copy Number Assay used was Hs00228043_cn. Target gene DKK3 located on Chr.11:11989984 on NCBI build 37. Housekeeping gene Ribonuclease P RNA Component H1, RPPH1 located on Chr.14:20811565 on NCBI build 37.

\section{Immunofluorescence (IF) detection of proteins}

Five $\mu \mathrm{M}$-thick FFPE sections were processed for immunofluorescence detection of DKK3 and $\beta$-catenin proteins as described previously [31]. Goat anti-DKK3 polyclonal (SC14959; 1:100 dilution) or mouse anti- $\beta$ catenin monoclonal (SC47778; 1:200 dilution) primary antibodies and anti-goat FITC (fluorescein isothiocyanate) and anti-mouse TR (Texas Red) secondary antibodies (1:1000) were used, followed by Ultracruz mounting agent containing 4',6-diamidino-2-phenylindole (DAPI) (all from Santa Cruz Biotechnology, Inc.) for indirect immunodetection. A Zeiss AX10 confocal microscope with AxioVision 4.8 program was used for IF analysis, and photomicrographs were taken at a total magnification of $100 \times$ or $400 \times$, as noted.

\section{Cell culture, expression vectors, transfections, and western blot detection}

American Type Culture Collection (ATCC)-authenticated human ACC cell lines SW-13 (CCL-105) and NCI-H295R (CRL-2128) were maintained in growth conditions recommended by ATCC, as reported previously [31]. For DKK3 treatments, a working concentration of $5 \mu \mathrm{g} / \mathrm{mL}$ (in PBS) of human recombinant DKK3 (R\&D Systems) was used. RNAi silencing was carried out with 3 unique 27-mer siRNA duplexes (designated $\mathrm{siA}, \mathrm{siB}$, and $\mathrm{siC}$ ) targeting DKK3 (Human) and FOXO1 (Human) transcripts. Universal scrambled negative control siRNA was used as nonspecific control (all from Origene). Lipofectamine2000mediated transfection was carried out in Opti-MEM according to manufacturer's recommendations (ThermoFisher Scientific) in 6-well plates with starting densities of 50,000 cells/well for SW-13 and 80,000 cells/well for NCIH295R. Transfection medium was replaced with regular growth medium after $24 \mathrm{~h}$ of transfection. Cells were lysed for RNA extraction (after $24 \mathrm{~h}$ ) or protein extraction (after $48 \mathrm{~h}$ ), and assays were done $48 \mathrm{~h}$ post-transfection.

Myc-DDK tagged pCMV6-Entry, pCMV6-Entry/GFP, and pCMV6-Entry/DKK3 plasmid vectors (Origene) were used for transient and stable expression. Transient transfection was carried out in Opti-MEM medium using Lipofectamine2000 according to manufacturer's recommendations (ThermoFisher Scientific) in 6-well plates with starting densities of 50,000 cells/well for SW-13 and 80,000 cells/ well for NCI-H295R cells. Cells were transfected one day after plating. Transfection medium was replaced with appropriate growth medium $6 \mathrm{~h}$ post-transfection, and cells were assayed for cell behaviors $24 \mathrm{~h}$ post-transfection. Total cell numbers and viability were calculated by staining cells with $0.4 \%$ Trypan Blue (ThermoFisher Scientific) and counting with hemocytometer (Hausser Scientific Co.). Experiments were performed in triplicate, and parallel pCMV6-Entry/GFP transfections were used to determine transfection efficiency.

Stable Geneticin (G418)-resistant pCMV6-Entry, pCMV6-Entry/GFP, and pCMV6-Entry/DKK3 transfected clones were selected in $800 \mu \mathrm{g} / \mathrm{mL}$ G418-containing growth medium (ThermoFisher Scientific). Multiple clones were then pooled into populations to avoid expression variability and selection bias between clones. Established populations 
designated SW-Neo (from pCMV6-Entry transfections) and SW-DKK3 (expressing Myc-DDK/DKK3) were compared to parental SW-13 cells to determine effects of constitutive DKK3 expression on SW-13 cells' malignant properties. Constitutive DKK3 expression was confirmed via qRT-PCR using TaqMan primer/probe pairs (ThermoFisher Scientific) and Western blotting using anti-DKK3 mAb (1:500; Abcam), anti-mouse-HRP (Santa Cruz Biotechnologies, Inc.), Mini-PROTEAN TGX gel, PVDF blotting membrane (Bio-Rad), and enhanced chemiluminescence (ECL) detection reagents (ThermoFisher Scientific) as per manufacturer's protocols. Unless specified, $100 \mu \mathrm{g}$ protein was loaded per well of $4-10 \%$ SDS gels (Bio-Rad). Equal protein loading was confirmed by staining PVDF membranes with GelCode Blue Safe Protein stain (ThermoFisher Scientific) after chemiluminescence detection.

\section{Flow cytometric analysis of cell cycle}

SW-13, SW-Neo, and SW-DKK3 cells were fixed in cold $70 \%$ ethanol for $30 \mathrm{~min}$ at $4{ }^{\circ} \mathrm{C}$, washed twice with PBS, treated with ribonuclease $(100 \mu \mathrm{g} / \mathrm{mL})$, and stained with propidium iodide (PI; $50 \mu \mathrm{g} / \mathrm{mL}$ in PBS). Using bandpass filter $605 \mathrm{~nm}$ (for PI), forward and side scatter were measured in a BD LSRII Flowcytometer. Pulse processing was used to exclude cell doublets from the analysis. FlowJo software was used to analyze the best Gaussian distribution curve to each peak for the cell populations of G0-G1 and G2-M.

\section{Cell invasion, migration, adhesion, and clonogenic growth assays}

To assess invasive proficiencies, 100,000 SW-13, SW-Neo, or SW-DKK3 cells were allowed to invade through Matrigel from upper chambers containing serum-free medium to lower chambers containing 10\% FBS medium in BD BioCoat Matrigel invasion chambers (BD Biosciences). After $24 \mathrm{~h}$, Matrigel was removed, and invaded cells were fixed in $3.7 \%$ formaldehyde/PBS (10 min), stained with $0.05 \%$ crystal violet (30 min), and counted at $100 \mathrm{X}$ magnification with light microscope. Matrigel invasion assay was performed twice in triplicate chambers. In migration assays, 100,000 cells were allowed to migrate through $8 \mu \mathrm{M}$-pore size modified Boyden Chambers (BD Biosciences) from upper chambers containing serum-free medium to lower chamber with 10\% FBS medium. After 4 or $8 \mathrm{~h}$, cells that migrated to lower side of the membrane were fixed, stained, and counted as above.

Cell adhesion assays were carried out in 6-well plates. One hundred thousand cells were seeded per well, allowed to grow overnight, washed with warm PBS, and incubated with $0.5 \mathrm{~mL}$ of $0.25 \%$ Trypsin-EDTA for $1 \mathrm{~min}$; TrypsinEDTA was then removed, plates were tapped gently to remove loosely attached cells, cells were washed with $10 \%$ FBS medium, fixed, stained and counted as above. For clonogenic growth assays, cells were seeded in 6-well plates at low densities (5,000 cells/well) and allowed to grow 7 days in appropriate growth medium (SW-Neo and SW-DKK3) with medium change every 3 days. On day 7 , cells were washed with PBS, fixed, and stained as above. Colonies with $12 \pm 2$ or $4 \pm 2$ cells were counted as separate groups and averaged from 6 wells. Experiments were repeated 3 times, and data from a representative experiment is presented.

\section{Statistical analysis}

Normal distribution of continuous variables was assessed using D'Agostino and Pearson omnibus tests. Normally distributed variables were analyzed using 2-tailed $t$ test; Mann-Whitney $U$ test was used for non-normally distributed variables. For variables with greater than 2 dependent values, a 1-way analysis of variance and Kruskal-Wallis tests were used for normally and nonnormally distributed populations, respectively. Matched continuous variables were compared using Pearson correlation. Survival data were assessed by Kaplan-Meier methods, and differences were compared by Mantel-Cox test. Statistical analyses were performed using Prism 6 (GraphPad Software).

\section{Results}

Reduced expression of DKK3 in adrenocortical carcinoma Recent comprehensive genetic analyses identified WNT signaling as the most common target of genetic aberrations in ACCs. To identify novel WNT targets, we compared the expression pattern of selected positive and negative WNT regulators in 7 ACC samples using an expanded WNT expression array. Among various differentially expressed WNT regulators, the expression of DKK3, a negative WNT regulator and a putative tumor suppressor in a wide variety of tumors, was found significantly reduced in the majority (6/7) of the ACC samples tested (Fig. 1a; Additional file 1: Figure S1). Further, compared to the robust expression pattern in adrenal cortex, DKK3 protein expression was found to be nearly absent in ACCs by indirect immunofluorescence analysis (Fig. 1b; a\&h). DKK3 was observed to be expressed in the zona fasciculata and zona reticularis (data not shown) in normal adrenal cortex, though to a lesser extent going inward from the zona glomerulosa (Fig. 1b). In contrast to the near absence of DKK3, $\beta$-catenin appeared to be over-expressed in ACC (Fig. 1b; h). Moreover, both robustly expressed DKK3 and weakly expressed $\beta$-catenin proteins were found predominantly in the cytoplasmic compartment of normal adrenal cortex (Fig. 1b; b-g), while increased $\beta$ catenin levels were found both in the cytoplasm and the nuclei of ACC cells (Fig. 1b; i-n). Due to the rarity of the disease and scarcity of fresh-frozen samples, an international patient cohort $(n=38)$ was assembled for DKK3 


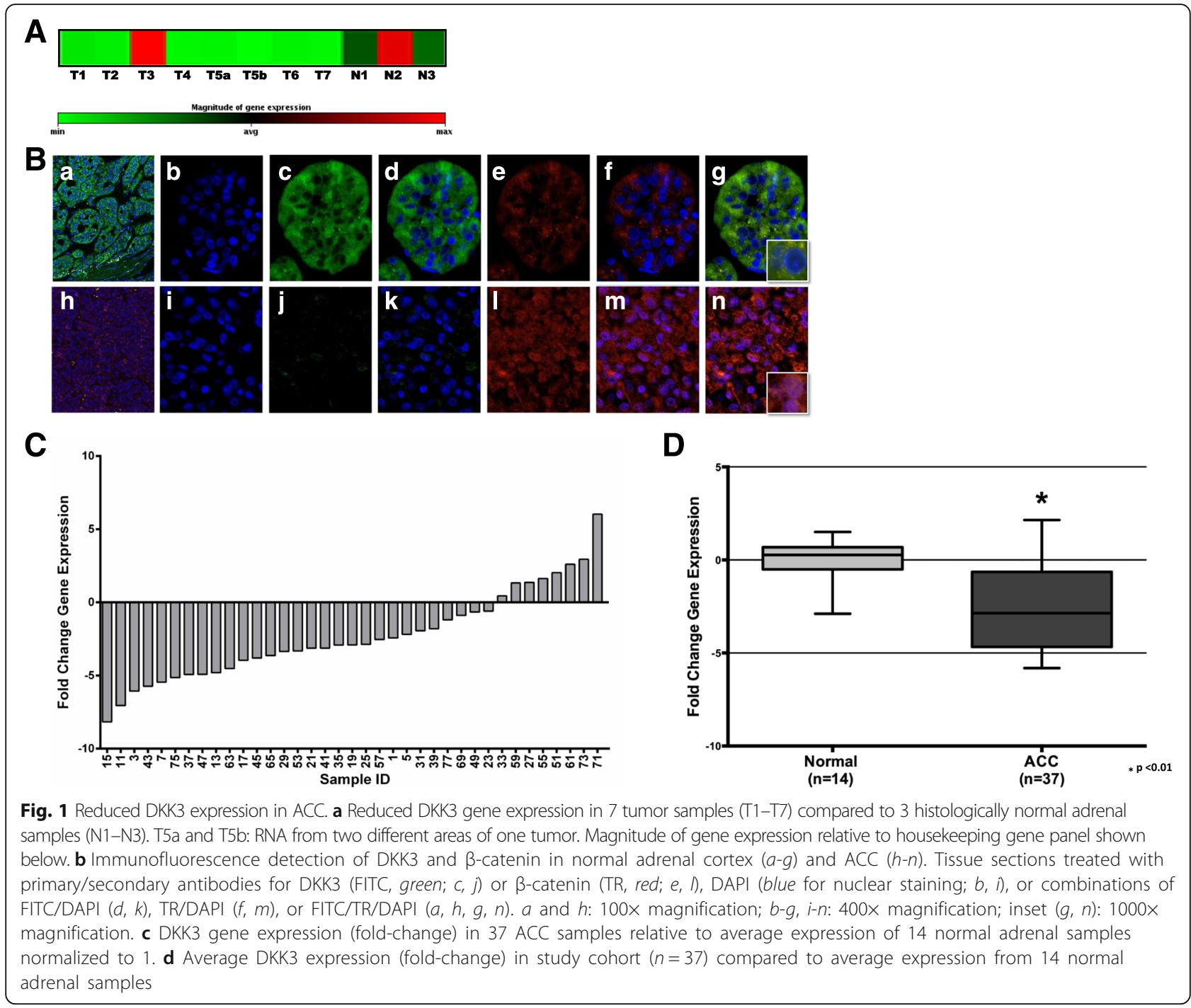

expression analysis (Table 1). Quantitative RT-PCR analysis of 37 ACC samples confirmed reduced mRNA expression in the majority $(70 \% ; 26 / 37)$ of ACC samples (Fig. 1c). The mean expression of DKK3 in 37 ACCs was significantly decreased $(p=0.002)$ compared to mean DKK3 expression in 14 normal adrenal tissue samples (Fig. 1d). The high frequency of DKK3 silencing (70\%) observed in ACCs is very similar to that observed in other malignancies including thyroid [32] and pancreatic cancers [33].

To determine whether reduced DKK3 expression correlated with disease presentation and/or outcome, we analyzed statistical correlation to various patient characteristics (Table 1), including age, gender, tumor size, tumor weight, ENSAT stage, and hormone secretion phenotypes. Despite the limited cohort size $(n=38)$, reduced DKK3 expression showed a non-significant trend $(p=0.062)$ towards female gender (Additional file 1: Figure S2). Kaplan-Meier survival analysis also did not reveal a significant effect on survival in patients with reduced DKK3 expression $(p=0.19)$ (Additional file 1: Figure S3).

\section{DKK3 promoter methylation and gene copy number alterations in ACC}

Promoter methylation has been identified as the principal mechanism of DKK3 silencing in multiple tumor types [34-39]. Moreover, we have previously shown potential involvement of global and gene-specific promoter methylation changes in ACCs [40]. Using the EpiTect protocol [31], we analyzed methylation status of the DKK3 promoter in 9 normal adrenal tissue and 29 ACC samples. Compared to the DKK3 promoter methylation status in normal adrenal DNA, 4 ACC samples (14\%) showed marked levels of hypermethylation, and 14 samples (48\%) showed intermediate-range methylation (Table 2). Twelve of 18 ACC samples with hyper- or intermediate promoter methylation $(67 \%)$ also showed significant reduction in DKK3 expression, concurring with the established role of 
Table 1 Summary of cohort demographics and patient characteristics

\begin{tabular}{|c|c|c|}
\hline Characteristics & Number of Cases & Percentage \\
\hline Total Number & 38 & NA \\
\hline \multicolumn{3}{|l|}{ Gender } \\
\hline Male & 14 & $35.8 \%$ \\
\hline Female & 24 & $63.2 \%$ \\
\hline Age $\pm S D(y)$ & $57.7 \pm 13.2$ & NA \\
\hline \multicolumn{3}{|l|}{ Cohort } \\
\hline Yale & 10 & $26.3 \%$ \\
\hline Karolinska & 25 & $65.8 \%$ \\
\hline Düsseldorf & 3 & $7.9 \%$ \\
\hline \multicolumn{3}{|l|}{ Tumor Size (cm) } \\
\hline Mean \pm SD & $12.8 \pm 4.4$ & NA \\
\hline Range & $5.5-21.0$ & NA \\
\hline \multicolumn{3}{|l|}{ ENSAT 2008 Stage } \\
\hline । & 0 & $0.0 \%$ \\
\hline$\|$ & 18 & $47.4 \%$ \\
\hline III & 11 & $28.9 \%$ \\
\hline IV & 9 & $23.7 \%$ \\
\hline \multicolumn{3}{|l|}{ Hormone Hypersecretion } \\
\hline Aldosterone & 1 & $2.6 \%$ \\
\hline Cortisol & 9 & $23.7 \%$ \\
\hline Androgen/DHEA & 4 & $10.5 \%$ \\
\hline Estrogen & 1 & $2.6 \%$ \\
\hline Multi-secreting ${ }^{a}$ & 5 & $13.2 \%$ \\
\hline Non-functional & 14 & $36.8 \%$ \\
\hline No information available & 4 & $10.5 \%$ \\
\hline \multicolumn{3}{|l|}{ Outcome } \\
\hline Alive, no recurrence & 11 & $28.9 \%$ \\
\hline Alive, recurrence & 5 & $13.2 \%$ \\
\hline Death from disease & 16 & $42.1 \%$ \\
\hline Death from other causes & 4 & $10.5 \%$ \\
\hline Lost to follow-up & 2 & $5.3 \%$ \\
\hline
\end{tabular}

aTumors secreting two or more of the following hormones: aldosterone cortisol, testosterone, or DHEA

y years, $\mathrm{cm}$ centimeter, SD standard deviation, ENSAT European Network for the Study of Adrenal Tumors, DHEA dehydroepiandrosterone, NA

not applicable

promoter methylation in $D K K 3$ silencing in other tumors [36, 37]. Interestingly, 8/11 samples with non-methylated promoters also showed comparable frequency of $D K K 3$ silencing (72\%), suggesting alternate mechanisms for DKK3 down-regulation in ACC.

Recent genetic analyses of ACCs by us and others have shown significant copy number alterations in genes potentially involved in various signaling pathways [30]. To determine if gene copy loss contributed to reduced expression of DKK3 in this cohort of ACC samples, we
Table 2 DKK3 mRNA expression, promoter methylation, and gene copy number alterations in adrenocortical carcinoma

\begin{tabular}{|c|c|c|c|}
\hline Sample & Gene Expression & Promoter Methylation & Gene Copy Number \\
\hline 1 & $L$ & $\mathrm{IM}$ & 2 \\
\hline 3 & $L$ & $\mathrm{HM}$ & 2 \\
\hline 5 & L & $\mathrm{HM}$ & 2 \\
\hline 7 & $L$ & UM & 1 \\
\hline 11 & L & UM & 1 \\
\hline 13 & L & UM & 2 \\
\hline 15 & L & UM & ND \\
\hline 17 & L & UM & 1 \\
\hline 19 & L & $\mathrm{HM}$ & 1 \\
\hline 21 & L & $\mathrm{IM}$ & 2 \\
\hline 25 & $L$ & $\mathrm{IM}$ & 2 \\
\hline 29 & L & $\mathrm{IM}$ & 1 \\
\hline 31 & L & $\mathrm{IM}$ & 2 \\
\hline 35 & L & ND & ND \\
\hline 37 & L & ND & ND \\
\hline 39 & L & ND & ND \\
\hline 41 & $L$ & $\mathrm{IM}$ & 2 \\
\hline 43 & $L$ & ND & ND \\
\hline 45 & $L$ & UM & ND \\
\hline 47 & L & $\mathrm{IM}$ & 1 \\
\hline 53 & $L$ & $\mathrm{IM}$ & 1 \\
\hline 57 & L & $\mathrm{HM}$ & 6 \\
\hline 63 & $L$ & UM & 2 \\
\hline 65 & $L$ & UM & 3 \\
\hline 75 & L & ND & ND \\
\hline 77 & L & ND & ND \\
\hline 9 & ND & $\mathrm{IM}$ & 2 \\
\hline 23 & $\mathrm{~N}$ & UM & 2 \\
\hline 33 & $\mathrm{~N}$ & $\mathrm{IM}$ & 2 \\
\hline 49 & $\mathrm{~N}$ & $\mathrm{IM}$ & 2 \\
\hline 71 & $\mathrm{~N}$ & ND & ND \\
\hline 27 & $\mathrm{H}$ & $\mathrm{IM}$ & 1 \\
\hline 51 & $\mathrm{H}$ & $\mathrm{IM}$ & 3 \\
\hline 55 & $\mathrm{H}$ & $\mathrm{IM}$ & 1 \\
\hline 59 & $\mathrm{H}$ & UM & 2 \\
\hline 61 & $\mathrm{H}$ & UM & 2 \\
\hline 69 & $\mathrm{H}$ & ND & ND \\
\hline 73 & $\mathrm{H}$ & ND & ND \\
\hline
\end{tabular}

Abbreviations: DKK3 Dickkopf-related protein 3, L low expression, $N$ normal expression, $H$ high expression, UM unmethylated, IM intermediate methylation, $H M$ hypermethylation, $N D$ not determined

analyzed copy number variations using the TaqMan copy number assay. We found copy losses in 9 samples (33\%) and copy gains in 3 of 27 ACC samples tested (Table 2; 
Additional file 1: Figure S4). Seven of the 9 samples with copy loss (78\%) showed marked reduction in DKK3 expression; 4 showed concurrent $D K K 3$ promoter methylation. Interestingly, one ACC sample (ID \#57) with 6 copies of the DKK3 gene also showed promoter hypermethylation and reduced expression of DKK3.

\section{DKK3 silencing reduces clonogenic growth and promotes} migration of ACC cells

To test whether DKK3 plays a tumor suppressor role in ACC in vitro, we investigated the expression pattern and regulation of DKK3 in two ACC cell lines, SW-13 and NCIH295R. Western blot analysis showed modest expression of DKK3 in SW13 cells, while NCI-H295R cells showed low expression (Fig. 2a). Despite carrying TP53 gene mutations, non-hormone-secreting SW-13 cells maintain an unperturbed and modifiable WNT signaling pathway, whereas the adrenal hormone-producing NCI-H295R cells harbor CTNNB1 and axin1 mutations, resulting in constitutive WNT activation $[31,41]$. To test whether suppressing endogenous DKK3 will influence malignant properties of ACC cells, we used a transient siRNA-silencing method. Silencing of $D K K 3$ expression in SW-13 (Fig. 2b, d) and NCIH295R (Fig. 2c) cells with siRNA was confirmed by qRTPCR (Fig. 2b-c) and Western blot (Fig. 2d). DKK3 silencing did not result in significant loss of viability in either cell type for the duration of study (48 h). Due to low baseline levels of DKK3 in H295R (Fig. 2a), siRNA-mediated silencing has no detectable effect observable by Western (data not shown). Next, we examined whether silencing of DKK3 modulates clonal growth or migratory potential of ACC cells. Partial silencing (40\% suppression; Fig. 2c) of DKK3

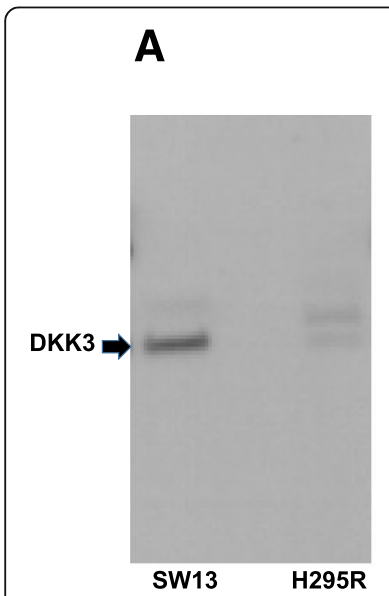

E

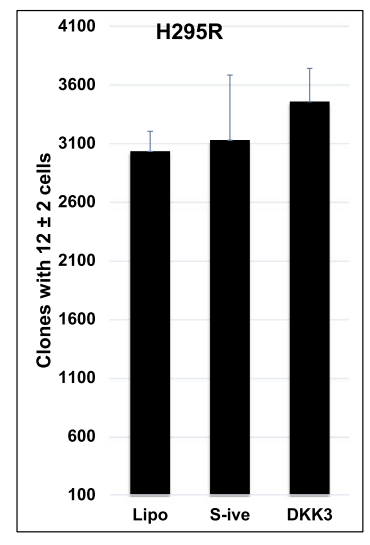

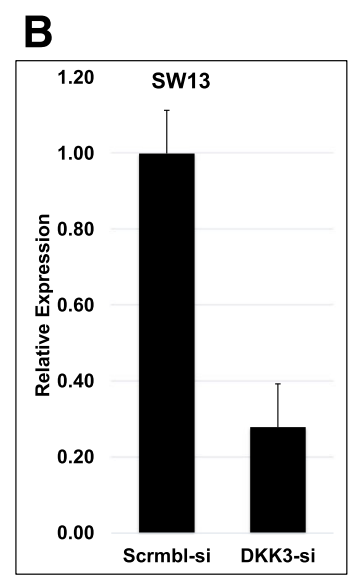

$\mathbf{F}$

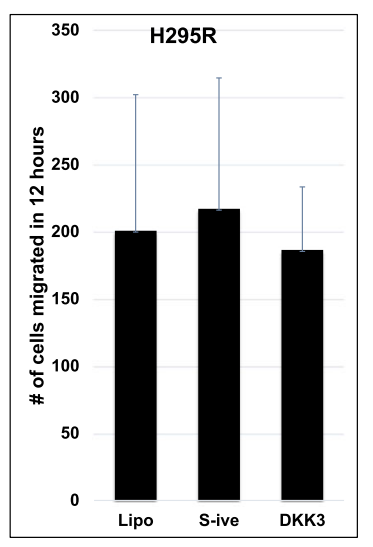

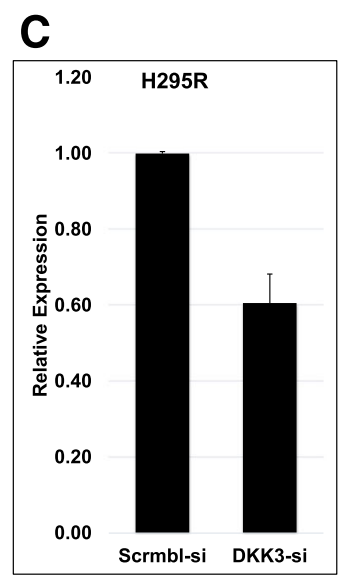

G

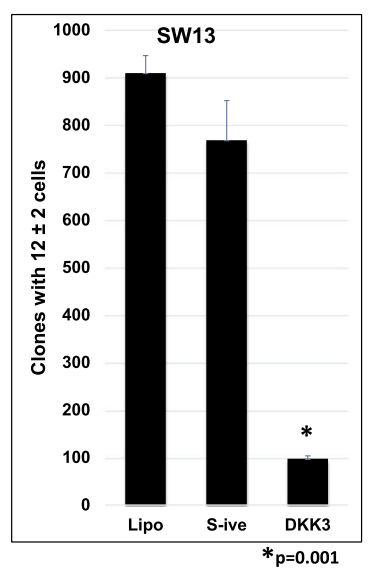

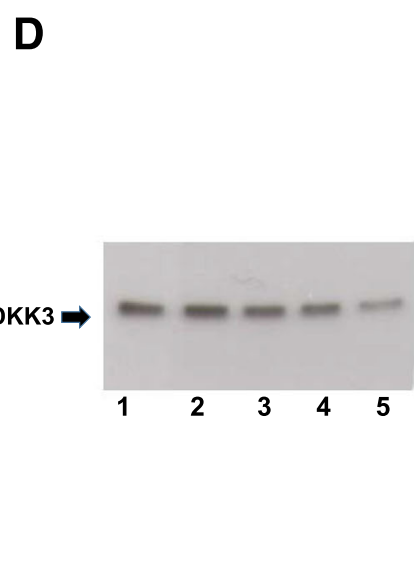

H

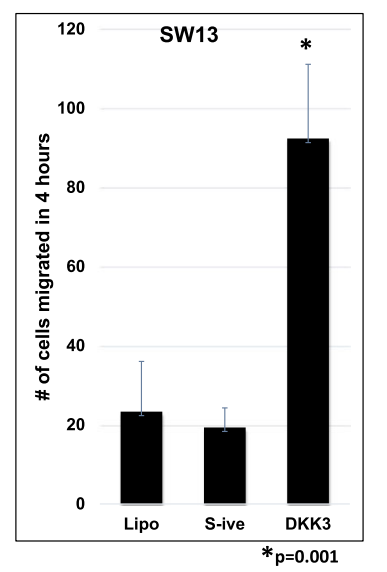

Fig. 2 RNAi silencing of DKK3 in ACC cell lines and effects on cell behavior. a Western immunoblot detection of endogenous DKK3 in SW-13 (left) and $\mathrm{NCl}-\mathrm{H} 295 \mathrm{R}$ (right). $\mathbf{b}$ and $\mathbf{c}$, Relative expression of DKK3 as determined by qRT-PCR in siRNA-treated SW-13 (2B) and NCI-H295R (2C) cells, normalized to expression in cells treated with scrambled siRNA for $24 \mathrm{~h}$. d Western immunoblot detection of DKK3 in SW-13 cells treated with control (1), scrambled negative siRNA (2), 10 (3), 20 (4), and 40 nM (5) DKK3 siRNAs for 24 h followed by protein extraction 48 h post-transfection. e-h, NCl-H295R (e and f) or SW-13 ( $\mathbf{g}$ and $\mathbf{h}$ ) cells treated with Lipofectamine (Lipo), scrambled negative siRNA (S-ive), or DKK3 siRNA (DKK3) for 24 h, allowed to grow in clonogenic growth conditions (e and $\mathbf{g}$ ), or allowed to migrate through modified Boyden chambers through growth factor concentration gradient for 12 (f) or 4 (h) hours. Clones with $12 \pm 2$ cells were fixed, stained, and counted with light microscope (e and $\mathbf{g}$ ); cells that migrated to lower side of modified Boyden chamber membranes were fixed, stained, and counted ( $\mathbf{f}$ and $\mathbf{h}$ ) 
(Fig. 2a) did not appear to influence clonogenic growth or migratory potentials of NCI-H295R cells (Fig. 2e-f). It is conceivable that the constitutively active WNT signaling in these cells may have conferred inherent resistance to DKK3 signaling. On the other hand, DKK3 silencing in SW-13 cells (75\% suppression; Fig. 2b; lane 5 of Fig. 2d) significantly impaired the cells' ability to form colonies in isolation $(p=0.001)$ (Fig. $2 \mathrm{~g}$ ) and promoted their motility behavior $(p=0.001)$ (Fig. 2h; Additional file 1: Figure S7). These results suggest a potential role for DKK3 silencing in adrenal carcinogenesis, which could be overrun by gain-of-function WNT mutations.

\section{Exogenous DKK3 promotes migration of SW-13 cells}

Reports suggesting distinct roles for endogenous and secreted DKK3s in cell behavior $[17,42]$ prompted us to test the effect of exogenous DKK3 addition to ACC cells. Cells grown in the presence of exogenous human recombinant DKK3 did not show a difference in their overall growth potentials (Additional file 1: Figure S5). However, migratory potential of SW-13 cells was found to be accentuated with exogenous DKK3 (Fig. 3a). The exogenous DKK3 in this instance appears to have a dominant effect over the motility-impeding effect of endogenous DKK3 (Fig. 3a \& f). NCI-H295R cells with constitutively active $\beta$-catenin appeared to be resistant (Fig. 3a) to the exogenous DKK3induced migration-promoting effects on SW-13 cells.

\section{Constitutive over-expression of DKK3 stifles malignant behavior of ACC cells}

DKK3 is constitutively expressed and persistently present during zonal differentiation of adrenal cortex [14]. To test whether constitutive over-expression of DKK3 promotes redifferentiation of ACC cells, we generated a stable population of SW-13 cells engineered to over-express DKK3. Since NCI-H295R cells exhibited no appreciable response to either endogenous or exogenous DKK3 (Figs. 2e-f and 3a), we limited our attention to SW-13 cells. Expression of ectopic DKK3 was confirmed (Fig. 3b), and SW-DKK3 cells were assessed for various malignant properties compared to parental SW-13 and control SW-Neo cells.

SW-DKK3 cells grew at a slower rate compared to both parental SW-13 and SW-Neo cells (Fig. 3c). The slow rate of growth of SW-DKK3 cells was found to be caused by an increase in the percentage of cells accumulated in G1 phase $(47.5 \%$ SW-Neo compared to $56.3 \%$ SW-DKK3 cells) of the cell cycle (Additional file 1: Figure S6). Since suppression of endogenous DKK3 expression resulted in reduced clonogenic growth and increased motility of SW13 cells, we compared clonal growth and migratory potential of SW-DKK3 cells to that of SW-Neo cells, using parental SW-13 cells as reference. Compared to their vector-transfected controls, SW-DKK3 cells showed an overall increase in clonal growth efficiency (Fig. 3d).
Interestingly, $52 \%$ of the clones were small ( $4 \pm 2$ cells) and composed of larger, slow-growing, or growth-arrested cells (Fig. 3e; right). In SW-Neo, this fraction of small clones represented only $9 \%$ of the clones $(p<0.001)$, while the remaining $91 \%$ constituted large colonies comprised of $12 \pm 2$ cells (Fig. $3 \mathrm{e}$; left).

Next, we assessed the effect of constitutive DKK3 over-expression on migratory potential of SW-13 cells. SW-DKK3 cells exhibited significantly decreased migratory potential compared to parental SW13 and SW-Neo cells $(p<0.001)$ (Fig. 3f). To test whether DKK3promoted reduction in SW-13 cells' migratory potential has a potential in vivo implication, we performed an in vitro invasion assay. As reported previously in other cancer types [26], over-expression of DKK3 significantly impaired SW-13 cells' ability to invade through reconstituted matrix $(p<0.001)$ (Fig. 3g).

\section{DKK3 promotes a more differentiated phenotype in ACC cells}

To test whether decreased invasive behavior of DKK3over-expressing SW-DKK3 cells is due to signaling changes that can potentially modulate cell spreading and thereby migration kinetics, cell morphology was observed under light microscopy. SW-DKK3 cells appeared to be larger with an extensive spreading phenotype aided by dysregulated cell edge attachments (Fig. 4a-c). While the parental SW-13 and SW-Neo cells displayed a significantly higher number of filopodia in a planar orientation, SW-DKK3 cells displayed a significantly higher proportion of lobopodial extensions $(p<0.01)$ (Fig. $4 \mathrm{a}$ d). To test whether the differential expression of cell extensions alters cell attachment characteristics, we performed a cell-detachment assay. SW-DKK3 cells showed a significantly stronger attachment to substratum compared to both SW-13 and SW-Neo cells $(p<0.01)$ (Fig. 4e). Whether increased attachment strength to substratum or multidirectional polarity conferred by the multitude of lobopodial attachments acts independently or in tandem towards reduced invasive behavior of SWDKK3 cells needs to be studied further.

\section{FOXO1 as a potential DKK3 target to effect redifferentiation}

Towards understanding the potential transcriptional modulation of cell adhesion and motility by DKK3 overexpression, we compared global difference in the expression pattern of 84 transcription factors using an expanded transcription array. Relative expression of 3 transcription factors, ID1, JUN, and FOXO1, consistently demonstrated $>4$-fold difference in expression between SW-DKK3 and SW-Neo/SW-13 cells (Additional file 1: Figure S8 A\&B). Transcription factors ID1 and JUN have been shown to mediate a variety of phenotypic effects, including apoptosis via 


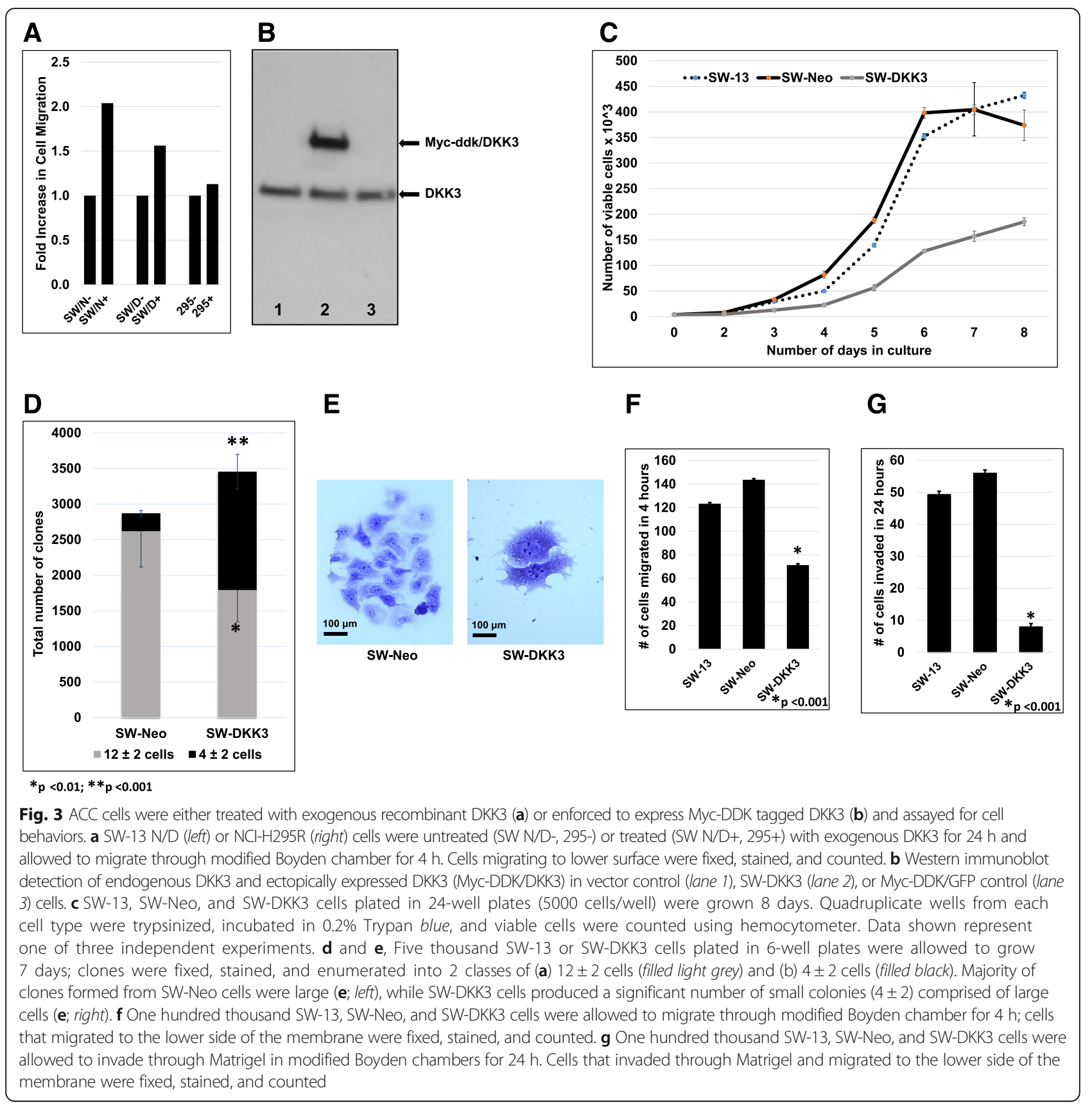

DKK3 signaling, in multiple cancers $(44,45)$. DKK3-stifled invasive behavior independent of loss of viability observed in SW-13 cells prompted us to investigate a potentially novel role for FOXO1 transcription factor in DKK3promoted redifferentiation of ACCs. Increased expression of FOXO1 in SW-DKK3 cells was confirmed by qRT-PCR (Additional file 1: Figure S8C). Using siRNA, we transiently silenced FOXO1 expression in SW-DKK3 and control SWNeo cells (Additional file 1: Figure S9A\&B) and assessed the effect of silencing on cell motility. Irrespective of DKK3 expression (Fig. 3b), both cell types showed an increase in migratory potential upon FOXO1 silencing (Fig. 5). The magnitude of relief in migratory inhibition was found to be more pronounced in SW-DKK3 cells (45\% increase in motility with $43 \%$ FOXO1 suppression) than in SW-Neo cells (30\% increase in motility with 66\% FOXO1 suppression; Additional file 1: Figure S10). These results clearly suggest a role for FOXO1 in mediating DKK3-promoted redifferentiation and/or anti-invasive signaling in SW-13 ACC cells.

\section{Discussion}

DKK3 expression is down-regulated in many human cancers, including that of the thyroid, lung, prostate, colon, breast, and liver [32, 33, 36, 43], but its 

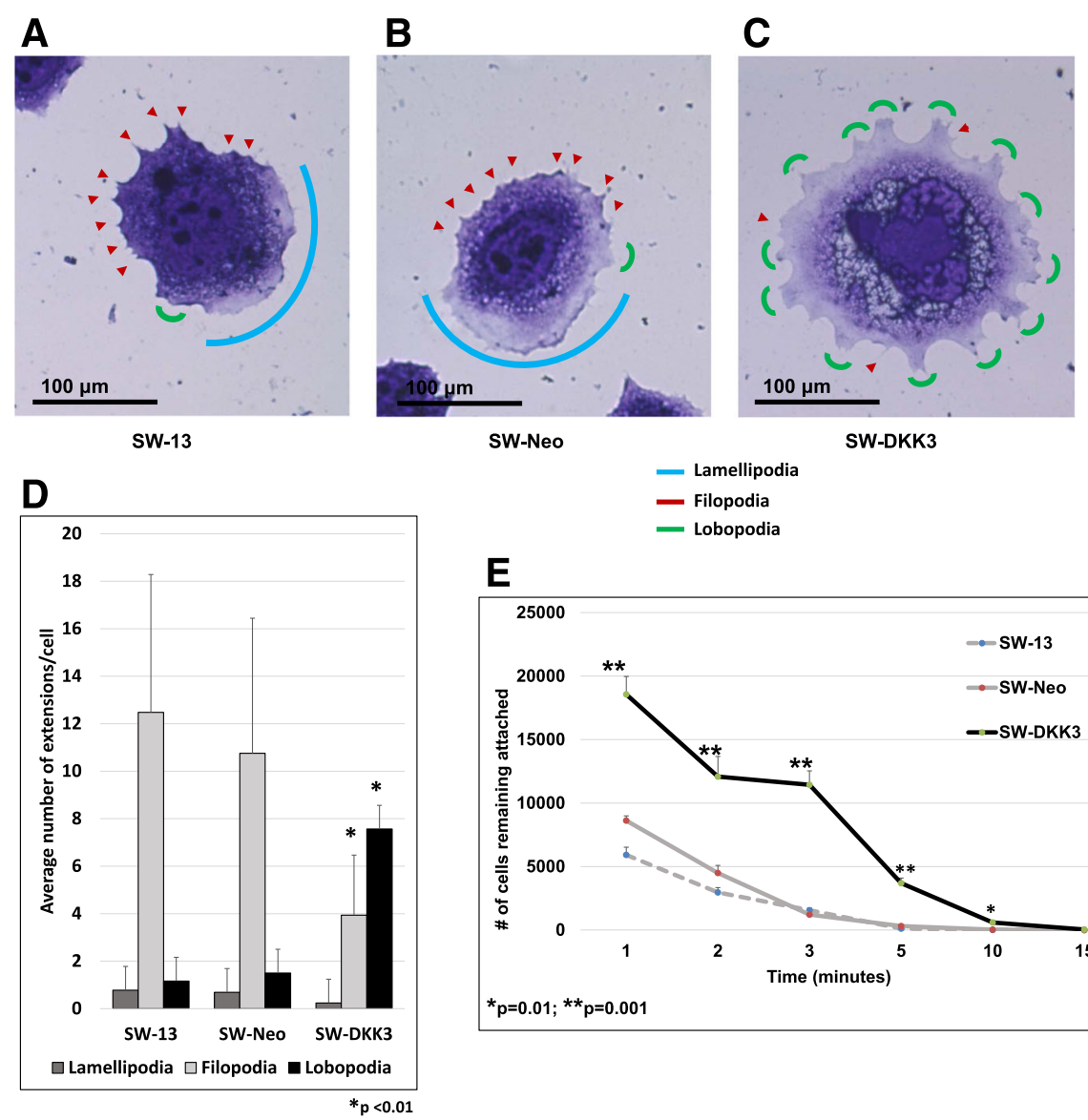

$\mathbf{E}$

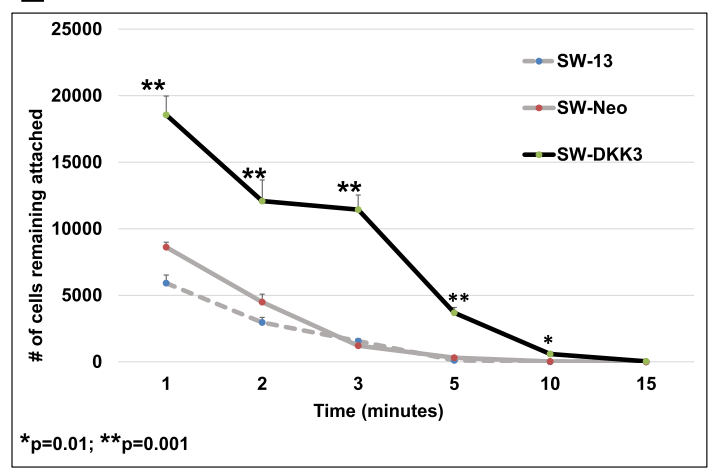

Fig. 4 Constitutive over-expression of DKK3 reorganizes cellular extensions and cell spreading. a-c SW-13 (a), SW-Neo (b), and SW-DKK3 (c) cells were grown on glass cover-slips, fixed, stained, and photographed. SW-13 and SW-Neo cells show a predominance of filopodia (red arrowheads) around edges; SW-DKK3 shows more lobopodia (small green arcs), absence of lamellipodia (blue arc), and few filopodia around edges. While cells in $\mathbf{a}$ and $\mathbf{b}$ appear to be polarized with filopodia at leading edge and lamellipodia at lagging edge, SW-DKK3 cells (c) show evenly spread flat lobopodia with extensive spreading and absence of polarity. Photomicrographs are taken using light microscope at 400x magnification. $\mathbf{d}$ Average number of lamellipodia, filopodia, and lobopodia per cell calculated from manual counting of cell extensions. Twenty randomly taken (400x magnification) photomicrographs of SW-13, SW-Neo, and SW-DKK cells used for quantification. e One hundred thousand SW-13, SW-Neo, and SW-DKK3 cells/well of 6-well plates were allowed to grow overnight, detached at specified times, cells remaining attached were fixed, stained, and counted manually

regulation in ACC is unclear. In this study, we utilized comprehensive genetic, epigenetic, and functional approaches to identify and characterize a potential tumor suppressor role for DKK3 in adrenal carcinogenesis. Our study showed a significant decrease in DKK3 expression in 70\% (25/37) of ACCs, strongly suggesting a tumor suppressor role for DKK3 in human adrenal tissue. Whether the observed silencing in malignant samples represents an earlier dedifferentiation or a later malignancy-promoting event needs to be determined. Despite the relatively small cohort size, this study did not find an association between DKK3 silencing and prognosis, unlike in gastric cancer [35]. Of note, the majority of this cohort of ACCs was previously shown not to harbor mutations in DKK3 or FOXO1 genes while $<10 \%$ carried betacatenin mutations [24].
Epigenetic modifications, including promoter methylation and chromatin condensation, have been proposed as major DKK3 silencing mechanisms in a variety of tumors [43]. This study also supports a role for promoter hypermethylation in DKK3 silencing in ACCs. Interestingly, DKK3 expression was also significantly decreased in many samples with intermediate methylation $(48 \%)$, suggesting that even intermediate levels of methylation may be adequate to silence DKK3 expression. Whether the $D K K 3$ promoter methylation observed in this study is a component of the global methylation changes observed in ACCs $[9,40]$ or a specific $D K K 3$ gene-targeted event needs to be clarified. A large proportion of the ACC study cohort with non-methylated promoters but with reduced DKK3 expression led us to seek alternate mechanisms for DKK3 down-regulation in ACC. In light of recent findings that gene copy number variations may 


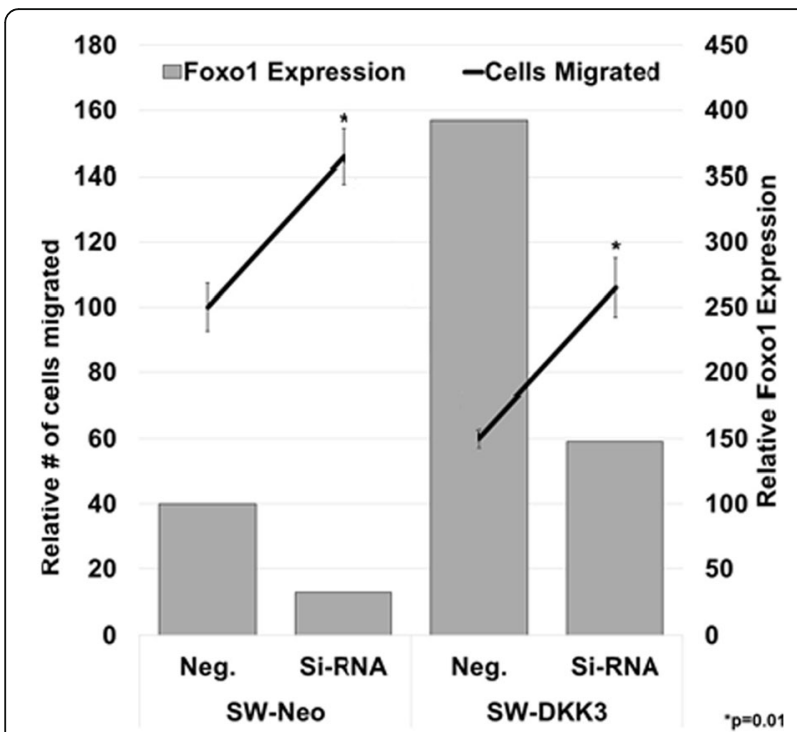

Fig. 5 FOXO1 silencing releases DKK3-mediated block of cell migration. Cells were treated with scrambled negative siRNA (Neg.) or FOXO1 siRNA (Si-RNA) for $24 \mathrm{~h}$, trypsinized, and allowed to migrate for $4 \mathrm{~h}$ through modified Boyden chamber. Migrated cells were fixed, stained, and counted manually. Total number of SW-Neo cells treated with scrambled siRNA normalized to $100 \%$, and relative change in migration of SW-Neo and SW-DKK3 cells treated with FOXO1 siRNA is shown in overlapping line graph on left Y-axis. Relative FOXO1 expression in SW-Neo and SW-DKK3 cells treated with FOXO1 siRNA, normalized to FOXO1

expression in SW-Neo cells treated with scrambled siRNA set at 100 shown as bars on right Y-axis

contribute to adrenocortical carcinogenesis $[8,24]$, we analyzed a portion of our samples for $D K K 3$ gene copy number variations. The majority of samples identified with $D K K 3$ copy loss also had significantly reduced DKK3 expression. Only a handful of these samples had concurrent promoter methylation, indicating a possible independent role for gene copy loss in causing DKK3 down-regulation in ACC. One ACC sample with 6 copies of $D K K 3$ and a hypermethylated promoter had significantly reduced expression of DKK3, suggesting that copy number variations may occur earlier in ACC oncogenesis than gene-specific methylation events.

Statistical correlation to patient characteristics and outcomes did not reveal any prognostic association of reduced DKK3 expression in ACC patients, although reduced DKK3 expression was found to trend non-significantly toward female gender. This study did not reveal a relationship between DKK3 expression and aldosterone biosynthesis, as reported earlier [25]. In addition, no significant correlation was observed in our tumor cohort between DKK3 expression, metastasis, and tumor grade.

We used functional approaches to characterize the effects of DKK3 on human ACC cells. Silencing of DKK3 in SW13, a human ACC cell line with intact and inductile WNT signaling and endogenously expresses DKK3, did not affect growth or viability of cells but resulted in reduced clonogenic growth and increased motility, consistent with a tumor suppressor role for DKK3 [31, 41]. In contrast, exogenous addition of DKK 3 to SW-13 cells resulted in increased motility, suggesting distinct roles for intracellular and secreted DKK3s. This observation is consistent with recent suggestions that DKK3 potentially has distinct intracellular signaling partners independent of canonical WNT- $\beta$-catenin circuitry [26]. Overall, intracellular DKK3 appears to confer a more differentiated phenotype to SW-13 cells. Whether the observed DKK3-promoted more differentiated phenotype is through (a) reactivation of the proposed adrenocortical differentiation pathway [14], (b) blocking of malignancy signaling networks, or (c) activation of a novel redifferentiation pathway needs to be clarified.

Light microscopic analysis revealed drastic changes in organization of cell outgrowths on the edges of slowmoving SW-DKK3 cells. While parental SW-13 and SWNeo cells produced an overwhelming number of dynamic filopodia that confer polarity and promote directional movement (41-43), SW-DKK3 cells showed predominantly lobopodia, indicative of multipolar spreading and hence arrested motility [44-46]. Although DKK3 has previously been shown to influence migratory and invasive phenotypes in multiple cancer cell types, an association of cell surface modifications that can impact cell mobility has not been shown. The mechanism(s) that elicit the observed changes in cell extension repertoire need to be investigated further. The association of the dedifferentiated phenotype and loss of DKK3 expression in ACC, combined with the re-acquisition of a relatively more differentiated phenotype in SW-13 ACC cells overexpressing DKK3, suggest a global differentiation role for DKK3 in adrenal cortex and the possibility that DKK3 could serve as a re-differentiation therapeutic target.

To explore potential pathways involved in eliciting the observed DKK3-promoted redifferentiated phenotype of ACC cells, we compared the expression pattern of $84 \mathrm{hu}-$ man transcription factors. Of the 3 transcription factors found to be over-expressed in SW-DKK3 cells (ID1, JUN and FOXO1), FOXO1 secured our immediate attention for 3 primary reasons: (1) FOXO1 is known to promote functional differentiation of myofibroblasts [47], (2) FOXO1 inhibits osteosarcoma malignancy via WNT inhibition [48], and (3) FOXO1 transcription has been suggested in response to steroid hormones [49]. We hypothesized that intracellular DKK3 promotes cellular differentiation signaling encompassing cellular spreading and stifled motility, at least in part, via FOXO1 up-regulation. FOXO1 RNAi silencing resulted in partial reversal of the motility suppression, suggesting that FOXO1 may indeed play a role in DKK3promoted redifferentiation of ACC cells. Based on the inverse relationship observed in ACC tissue between DKK3 
and beta-catenin expression, it can be assumed that DKK3/ FOXO1 regulation of malignant behavior of SW-13 cells is mediated through beta-catenin signaling. However, the precise DKK3-FOXO1 signaling circuitry in the context of adrenocortical differentiation needs to be investigated further.

\section{Conclusions}

In conclusion, we demonstrate for the first time that DKK3 expression is frequently reduced in ACC, potentially contributing to adrenal dedifferentiation and/or progression of malignancy. Further, we identified FOXO1 as a downstream effector of $D K K 3$ that may play a role in blocking adrenocortical dedifferentiation. These results suggest a potential for developing novel redifferentiationfocused pharmaceuticals that could allow successful treatment of ACCs when used in concert with existing treatment regimens.

\section{Additional file}

Additional file 1: Figure S1-S10. Supplementary Figures S1-S10. (PPTX $34931 \mathrm{~kb}$ )

\section{Abbreviations}

ACC: Adrenocortical carcinoma; DKK3: Dickkopf-related protein 3; FBS: Fetal bovine serum; FF: Flash-frozen; FFPE: Formalin-fixed, paraffin-embedded; FITC: Fluorescein isothiocyanate; FOXO1: Forkhead Box Protein O1; H\&E: Hematoxylin \& eosin; RPLPO: Ribosomal protein lateral stalk subunit PO; RPPH1: Ribonuclease P RNA component H1; TR: Texas Red

\section{Acknowledgments}

We would like to thank Drs. Irene Esposito and Henry Mayringer of Department of Pathology, Heinrich Heine University, Düsseldorf, Germany for their contributions.

\section{Funding}

This work was supported by the Damon Runyon Cancer Research Foundation (T.C.), the Ohse Research Foundation (T.C.B.), and a Medical Student Research Fellowship from the NIH - NHLBI (J.C.). None of the funding bodies played a role in data collection, analysis, or interpretation of data, the writing of the manuscript, or the decision to submit the manuscript for publication.

\section{Availability of data and materials}

All data generated or analyzed during this study are included in this published article and its Additional file 1: Figure S1-S10.

\section{Authors' contributions}

JYC and TCB participated in all aspects of studies and contributed equally to the manuscript. TCB conducted DKK3 expression, promoter methylation, CNV assays, Yale cohort clinical correlations, and statistical analyses, and drafted pertinent manuscript sections. JYC performed cell culture, transfections, cell growth, migration and invasion assays, Western blots, FACS analyses, drafted the rest of the manuscript, and was responsible for revisions. TDM and AS carried out transcription array analysis and FOXO1 siRNA studies. JMH conducted WNT array analysis. AS, CCJ, and CL were responsible for $\mathrm{KI}$ patient recruitment, disease characterization, and collection of nucleic acids, while WTK AK, and UIS were responsible for patient recruitment, disease characterization, and collection of nucleic acids in the Dusseldorf cohort. MLP performed histopathological analysis. RK performed light and fluorescence microscopy. TC conceived the research design, secured funding for the study, and participated in experimental design and data analysis. All authors read, participated in the critical revision of, and approved the final manuscript.

\section{Competing interests}

The authors declare that they have no competing interests.

\section{Consent for publication}

Not applicable.

Ethics approval and consent to participate

Written informed consent was obtained from patients prior to surgical resection of adrenal tissue according to protocols approved by Institutional Review Boards at (a) Yale University, New Haven, CT, USA, HIC\#0812004538 (b) Heinrich Heine University Düsseldorf, Düsseldorf, Germany, and (c) Karolinska Institutet, Stockholm, Sweden.

\section{Author details}

${ }^{1}$ Department of Surgery \& Yale Endocrine Neoplasia Laboratory, Yale University School of Medicine, New Haven, CT, USA. ${ }^{2}$ Department of Pathology, Yale University School of Medicine, New Haven, CT, USA. ${ }^{3}$ Department of Oncology-Pathology, Karolinska Institutet, Karolinska University Hospital, CCK, Stockholm, Sweden. ${ }^{4}$ Department of Surgery, Medical School, Heinrich Heine University, University Hospital Düsseldorf, Düsseldorf, Germany. ${ }^{5}$ Department of Nephrology, Medical School, Heinrich Heine University, University Hospital Düsseldorf, Düsseldorf, Germany. ${ }^{6}$ Department of Surgery, Yale University School of Medicine, 333 Cedar Street, FMB130A, New Haven, CT 06520, USA.

Received: 7 April 2016 Accepted: 22 February 2017

Published online: 01 March 2017

\section{References}

1. Lebastchi AH, Kunstman JW, Carling T. Adrenocortical carcinoma: current therapeutic state-of-the-art. J Oncol. 2012;2012:234726.

2. Dackiw AP, Lee JE, Gagel RF, Evans DB. Adrenal cortical carcinoma. World J Surg. 2001;25:914-26.

3. $\mathrm{Ng} \mathrm{L}$, Libertino JM. Adrenocortical carcinoma: diagnosis, evaluation and treatment. J Urol. 2003;169:5-11.

4. Berthon A, Martinez A, Bertherat J, Val P. Wnt/beta-catenin signalling in adrenal physiology and tumour development. Mol Cell Endocrinol. 2012; 351:87-95.

5. Lehmann T, Wrzesinski T. The molecular basis of adrenocortical cancer. Cancer Genet. 2012;205:131-7.

6. Simon DP, Hammer GD. Adrenocortical stem and progenitor cells: implications for adrenocortical carcinoma. Mol Cell Endocrinol. 2012;351:2-11.

7. Fonseca $\mathrm{AL}$, et al. Gene expression and regulation in adrenocortical tumorigenesis. Biology (Basel). 2012;2(1):26-39.

8. Assie G, Letouze E, Fassnacht M, Jouinot A, Luscap W, Barreau O, Omeiri H, Rodriguez S, Perlemoine K, Rene-Corail F, et al. Integrated genomic characterization of adrenocortical carcinoma. Nat Genet. 2014;46:607-12.

9. Fonseca AL, Healy J, Kunstman JW, Korah R, Carling T. Gene expression and regulation in adrenocortical tumorigenesis. Biology (Basel). 2012;2:26-39.

10. El Wakil A, Lalli E. The Wnt/beta-catenin pathway in adrenocortical development and cancer. Mol Cell Endocrinol. 2011;332:32-7.

11. Clevers H, Nusse R. Wnt/ $\beta$-catenin signaling and disease. Cell. 2012;149: 1192-205.

12. Brisken C, Heineman A, Chavarria T, Elenbaas B, Tan J, Dey SK, McMahon JA, McMahon AP, Weinberg RA. Essential function of Wnt-4 in mammary gland development downstream of progesterone signaling. Genes Dev. 2000;14: 650-4.

13. Jordan BK, Shen $\mathrm{JH}$, Olaso R, Ingraham HA, Vilain E. Wnt4 overexpression disrupts normal testicular vasculature and inhibits testosterone synthesis by repressing steroidogenic factor 1/beta-catenin synergy. Proc Natl Acad Sci U S A. 2003;100:10866-71.

14. Suwa T, Chen M, Hawks CL, Hornsby PJ. Zonal expression of dickkopf-3 and components of the Wnt signalling pathways in the human adrenal cortex. J Endocrinol. 2003:178:149-58.

15. Schimmer BP, White PC. Minireview: steroidogenic factor 1: its roles in differentiation, development, and disease. Mol Endocrinol. 2010:24:1322-37.

16. Heikkila M, Peltoketo $H$, Leppaluoto J, Ilves M, Vuolteenaho O, Vainio S. Wnt 4 deficiency alters mouse adrenal cortex function, reducing aldosterone production. Endocrinology. 2002;143:4358-65.

17. Niehrs C. Function and biological roles of the Dickkopf family of Wnt modulators. Oncogene. 2006;25:7469-81. 
18. Bernichtein S, Petretto E, Jamieson S, Goel A, Aitman TJ, Mangion JM, Huhtaniemi IT. Adrenal gland tumorigenesis after gonadectomy in mice is a complex genetic trait driven by epistatic loci. Endocrinology. 2008;149:651-61.

19. Howe LR, Subbaramaiah K, Chung WJ, Dannenberg AJ, Brown AM. Transcriptional activation of cyclooxygenase-2 in Wnt-1-transformed mouse mammary epithelial cells. Cancer Res. 1999;59:1572-7.

20. Valencia A, Roman-Gomez J, Cervera J, Such E, Barragan E, Bolufer P, Moscardo F, Sanz GF, Sanz MA. Wnt signaling pathway is epigenetically regulated by methylation of Wnt antagonists in acute myeloid leukemia. Leukemia. 2009;23:1658-66.

21. Gaujoux S, Pinson S, Gimenez-Roqueplo AP, Amar L, Ragazzon B, Launay P, Meatchi T, Libe R, Bertagna X, Audebourg A, et al. Inactivation of the APC gene is constant in adrenocortical tumors from patients with familial adenomatous polyposis but not frequent in sporadic adrenocortical cancers. Clin Cancer Res. 2010;16:5133-41.

22. Mitsui $Y$, Yasumoto H, Nagami T, Hiraki M, Arichi N, Ishikawa N, Araki A, Maruyama $\mathrm{R}$, Tanaka Y, Dahiya $\mathrm{R}$, Shiina $\mathrm{H}$. Extracellular activation of Wnt signaling through epigenetic dysregulation of Wnt inhibitory factor-1 (Wif-1) is associated with pathogenesis of adrenocortical tumor. Oncotarget. 2014:5:2198-207.

23. Bertherat J, Groussin L, Sandrini F, Matyakhina L, Bei T, Stergiopoulos S, Papageorgiou T, Bourdeau I, Kirschner LS, Vincent-Dejean C, et al. Molecular and functional analysis of PRKAR1A and its locus (17q22-24) in sporadic adrenocortical tumors: 17q losses, somatic mutations, and protein kinase A expression and activity. Cancer Res. 2003;63:5308-19.

24. Juhlin CC, Goh G, Healy JM, Fonseca AL, Scholl UI, Stenman A, Kunstman JW, Brown TC, Overton JD, Mane SM, et al. Whole-exome sequencing characterizes the landscape of somatic mutations and copy number alterations in adrenocortical carcinoma. J Clin Endocrinol Metab. 2015;100:E493-502.

25. El Wakil A, Bandulik S, Guy N, Bendahhou S, Zennaro MC, Niehrs C, Mari B, Warth R, Barhanin J, Lalli E. Dkk3 is a component of the genetic circuitry regulating aldosterone biosynthesis in the adrenal cortex. Hum Mol Genet. 2012;21:4922-9.

26. Veeck J, Dahl E. Targeting the Wnt pathway in cancer: the emerging role of Dickkopf-3. Biochim Biophys Acta. 1825;2012:18-28.

27. Lee EJ, Jo M, Rho SB, Park K, Yoo YN, Park J, Chae M, Zhang W, Lee JH. Dkk3, downregulated in cervical cancer, functions as a negative regulator of beta-catenin. Int J Cancer. 2009;124:287-97.

28. Hoang BH, Kubo T, Healey JH, Yang R, Nathan SS, Kolb EA, Mazza B, Meyers PA, Gorlick R. Dickkopf 3 inhibits invasion and motility of Saos-2 osteosarcoma cells by modulating the Wnt-beta-catenin pathway. Cancer Res. 2004;64:2734-9.

29. Saeb-Parsy K, Veerakumarasivam A, Wallard MJ, Thorne N, Kawano Y, Murphy G, Neal DE, Mills IG, Kelly JD. MT1-MMP regulates urothelial cell invasion via transcriptional regulation of Dickkopf-3. Br J Cancer. 2008;99:663-9.

30. Brown TC, Juhlin CC, Healy JM, Stenman A, Rubinstein JC, Korah R, Carling T. DNA copy amplification and overexpression of SLC12A7 in adrenocortical carcinoma. Surgery. 2016;159:250-8.

31. Korah R, Healy JM, Kunstman JW, Fonseca AL, Ameri AH, Prasad ML, Carling T. Epigenetic silencing of RASSF1A deregulates cytoskeleton and promotes malignant behavior of adrenocortical carcinoma. Mol Cancer. 2013;12:87.

32. Yin DT, Wu W, Li M, Wang QE, Li H, Wang Y, Tang Y, Xing M. DKK3 is a potential tumor suppressor gene in papillary thyroid carcinoma. Endocr Relat Cancer. 2013;20:507-14

33. Hsieh SY, Hsieh PS, Chiu CT, Chen WY. Dickkopf-3/RElC functions as a suppressor gene of tumor growth. Oncogene. 2004;23:9183-9.

34. Kobayashi K, Ouchida M, Tsuji T, Hanafusa H, Miyazaki M, Namba M, Shimizu $\mathrm{N}$, Shimizu K. Reduced expression of the REIC/Dkk-3 gene by promoterhypermethylation in human tumor cells. Gene. 2002;282:151-8.

35. Yu J, Tao Q, Cheng YY, Lee KY, Ng SS, Cheung KF, Tian L, Rha SY, Neumann $U$, Rocken C, et al. Promoter methylation of the Wnt/beta-catenin signaling antagonist Dkk-3 is associated with poor survival in gastric cancer. Cancer. 2009:115:49-60.

36. Veeck J, Bektas N, Hartmann A, Kristiansen G, Heindrichs U, Knuchel R, Dahl E. Wnt signalling in human breast cancer: expression of the putative Wnt inhibitor Dickkopf-3 (DKK3) is frequently suppressed by promoter hypermethylation in mammary tumours. Breast Cancer Res. 2008;10:R82.

37. Yang B, Du Z, Gao YT, Lou C, Zhang SG, Bai T, Wang YJ, Song WQ. Methylation of Dickkopf-3 as a prognostic factor in cirrhosis-related hepatocellular carcinoma. World J Gastroenterol. 2010;16:755-63.
38. Lodygin D, Epanchintsev A, Menssen A, Diebold J, Hermeking H. Functional epigenomics identifies genes frequently silenced in prostate cancer. Cancer Res. 2005;65:4218-27.

39. Chim CS, Pang R, Fung TK, Choi CL, Liang R. Epigenetic dysregulation of Wnt signaling pathway in multiple myeloma. Leukemia. 2007;21:2527-36.

40. Fonseca AL, Kugelberg J, Starker LF, Scholl U, Choi M, Hellman P, Akerstrom G, Westin G, Lifton RP, Bjorklund P, Carling T. Comprehensive DNA methylation analysis of benign and malignant adrenocortical tumors. Genes Chromosomes Cancer. 2012;51:949-60.

41. Durand J, Lampron A, Mazzuco TL, Chapman A, Bourdeau I. Characterization of differential gene expression in adrenocortical tumors harboring betacatenin (CTNNB1) mutations. J Clin Endocrinol Metab. 2011;96:E1206-11.

42. Papatriantafyllou M, Moldenhauer G, Ludwig J, Tafuri A, Garbi N, Hollmann G, Kublbeck G, Klevenz A, Schmitt S, Pougialis G, et al. Dickkopf-3, an immune modulator in peripheral CD8 T-cell tolerance. Proc Natl Acad Sci U S A. 2012;109:1631-6.

43. Liang L, He H, Lv R, Zhang M, Huang H, An Z, Li S. Preliminary mechanism on the methylation modification of Dkk-1 and Dkk-3 in hepatocellular carcinoma. Tumour Biol. 2015;36:1245-50.

44. Petrie RJ, Yamada KM. At the leading edge of three-dimensional cell migration. J Cell Sci. 2012;125:5917-26.

45. Krause M, Gautreau A. Steering cell migration: lamellipodium dynamics and the regulation of directional persistence. Nat Rev Mol Cell Biol. 2014;15:577-90.

46. Petrie RJ, Gavara N, Chadwick RS, Yamada KM. Nonpolarized signaling reveals two distinct modes of 3D cell migration. J Cell Biol. 2012;197:439-55.

47. Vivar R, Humeres C, Munoz C, Boza P, Bolivar S, Tapia F, Lavandero S, Chiong M, Diaz-Araya G. FoxO1 mediates TGF-beta1-dependent cardiac myofibroblast differentiation. Biochim Biophys Acta. 1863;2016:128-38.

48. Guan H, Tan P, Xie L, Mi B, Fang Z, Li J, Yue J, Liao H, Li F. FOXO1 inhibits osteosarcoma oncogenesis via Wnt/beta-catenin pathway suppression. Oncogenesis. 2015;4:e166.

49. Qin W, Pan J, Qin Y, Lee DN, Bauman WA, Cardozo C. Identification of functional glucocorticoid response elements in the mouse FoxO1 promoter. Biochem Biophys Res Commun. 2014;450:979-83.

\section{Submit your next manuscript to BioMed Central and we will help you at every step:}

- We accept pre-submission inquiries

- Our selector tool helps you to find the most relevant journal

- We provide round the clock customer support

- Convenient online submission

- Thorough peer review

- Inclusion in PubMed and all major indexing services

- Maximum visibility for your research

Submit your manuscript at www.biomedcentral.com/submit
Biomed Central 